\title{
Sistema al imentar e patrimônio imaterial: o chouriço no Seridó
}

\author{
Julie Antoinette Cavignac* \\ MaRIa ISABEL DANTAS**
}

\begin{abstract}
R esumo: O artigo apresenta dadbs etnográficos da festa da matança de porco e da produção de um doce - o chouriço na região do Seridó, no Rio Grande do Norte. Apresentado como um dos elementos definidores da identidade seridbense, o doce é analisadb aqui como patrimônio imaterial. Se o consumo de alimentos está ligadb a espaços, tempos, práticas, situações e comportamentos coletivamente vividos e imaginados, com a análise dessa prática alimentar, temos a oportunidade de explorar um sistema alimentar que informa sobre a organização e a lógica simbólica da sociedade sertaneja: é a ocasião de trocas, distribuições e retribuições quandb se realiza o exercício da reciprocidade, apesar de esses alimentos serem revestidos de tabus e interdições. Durante a festa é possível percebermos elementos do sistema simbólico local (valores, crenças, representações e tabus) e dos aspectos sociais. O forte simbolismo que envolve a came de porco e o sangue, bem como a sua ingestão, está relacionadb a fatores simbólicos, sociais e imaginários. Fatores estes responsáveis pela transformação de alimentos proibidos em "alimentos-dádiva" que são capazes de gerar relações sociais e revelar uma altura tradicional ainda performativa.
\end{abstract}

Palavr as-chave: sistema alimentar; identidade; tradição; festa; patrimônio imaterial

Les présents scellent le mariage, forment une parenté entre les deux couples de parents. IIs donnent aux 'deux cotés' même nature, et cette identité de nature est bien manifestée par I'interdit qui, dorénavant, tabouera, depuis le premier engagement de fiançailles, jusqu'à la fin de leurs jours, les deux groupes de parents qui ne se voient plus, ne s'adressent plus la parole, mais échangent de perpétuels cadeaux. En réalité, cet interdit exprime, et I' intimité et la peur qui règnent entre ce genre de créditeurs et ce genre de débiteurs réciproques. Que tel soit le príncipe, $c^{\prime}$ est ce que prouve ceci: le même tabou, significatif de l'intimité et de l'éloignement simultanés, s'établit encore entre jeunes gens des deux sexes qui ont passé en même temps par les cérémonies du ' manger de la tortue et manger

\footnotetext{
* Professora do DAN-UFRN

** Professora do Cefet-RN e doutoranda pelo PPGCSUFRN.
}

du cochon', et qui sont pour leur vie également obligés à l'échange de présents.

M arcel M auss (1950, p. 173)

A o se apropriarem da natureza, os homens a modificam: a alimentação, sistema simbólico complexo acionado no cotidiano, exemplifica uma modalidade dessa transformação (LéviStrauss, 1991). A decodificação dos sistemas alimentares auxilia na leitura das culturas humanas e na busca das suas lógicas, pois a al imentação informa sobre a maneira como os homens cultivam, escolhem, preparem seus alimentos. Além disso, descobrimos técnicas culinárias, ritmos diários, hábitos corporais, formas de comensalidade, sabores e cheiros elegidos por uma sociedade como deliciosos ou repugnantes. De um modo geral, durante a observação do longo processo que vai do cultivo de uma planta ou da criação de um animal atéa 
elaboração do alimento e a realização de uma festa, revelam-se formas de organização social, sistemas classificatórios e representações simbólicas inscritos nos discursos e nas práticas de um grupo determinado. Propomo-nos a realizar esse exercício com o estudo do chouriço, ${ }^{1}$ um doce de sangue preparado no Seridó, afim de afirmar como sistemas alimentares e simbólicos devem ser lidos em conjunto na decifração de um compl exo cultural que pode ser definido como patrimônio imaterial.

O Seridó, região situada no interior do Rio Grande do Norte, aparece como o epicentro da feitura desse doce exótico. Servido em qualquer hora do dia, o chouriço é uma combinação culinária de sangue e banha de porco, rapadura, castanha de caju, leite de coco, farinha de mandioca e especiarias (canela, erva-doce, cravo, pimenta-do-reino e gengibre). De sabor forte, devido às especiarias e ao doce da rapadura, 0 chouriço continua agradando o paladar seridoense. 0 chouriço é fortemente marcado por elementos do contexto rural, mesmo após ter surgido também nos núcleos urbanos nas últimas décadas do século XX. D efinido como alimento tradicional, renova-se e conserva a maioria de seus traços característicos, garantindo a permanência de uma cul tura local. Destarte a presença de valores da tradição, a produção do chouriço dá-se em novas temporalidades e historicidades (Santos, 1996, p. 116). É na tensão entre continuidade e mudança que é preparado 0 chouriço no Seridó. Sua produção requer 0 trabal ho de muitos, assim como para seu consumo, podendo ser considerado um "alimento-dom". ${ }^{2}$ Sua realização acontece em meio a

\footnotetext{
1. De acordo com o Novo Aurélio - século XXI (2002): Chouriço [De cor incerta; do lat. salsiciuru, poss.; cf. esp. chorizo.] S. m. 1. Enchido de porco, cujo recheio é misturado com sangue e curado ao fumo. [Sin. lus.: chouriça. Cf lingüiça (1).] 2. Saco longo e cilíndrico, cheio de areia ou serradura, para tapar as fendas inferiores das portas e janelas; chouriça. 3. Bras. Cul. Iguaria feita de sangue de porco, especiarias e açúcar. 4. Bras. RS Parte acolchoada do rabicho que passa por sob a cauda do cavalo. 5. A nt. Rolo de cabelo para altear o penteado. Há uma comida na região de Figueira em Portugal chamada de papa de moado que tem semeIhanças, pelos menos na forma de preparo e em alguns ingredientes, com o chouriço (o doce) encontrado no Nordeste brasileiro.

2. Termo utilizado por M auss (1978), para explicar o valor simbólico que os homens dão às coisas em determinadas situações.
}

uma festa, conhecida como matança de porco. A preparação do doce, geralmente supervisionada por senhoras de idade, envolve todo 0 grupo doméstico - a família estendida -, os parentes, vizinhos, amigos e al guns convidados especiais.

A pesar do seu caráter excepcional, o chouriço aparece como fundamental na constituição de víncul os sociais cotidianos. Existe uma lógica temporal e simbólica relacionada à festa do chouriço que pode ser expressa da seguinte forma: para o sangue perder seu poder natural e perigoso - isto é, ser transformado em comida -, são necessárias horas de cozimento em fogo baixo; tempo ideal para reunir parentes e amigos e festejar. 0 tempo cronológico tem importância menor na produção do chouriço, comparado ao da festa e do prazer. É nesse momento que a feitura dessa iguaria envolve um número significativo de pessoas conhecidas, que juntas mexem o doce e compartilham da festa, do trabal ho, da comida e externam um sentimento de fraternidade e relacionamento com seu lugar e sua cul tura. Festa que pode ser lida como uma "forma lúdica de sociação e como um fenômeno multiforme de vida coletiva" (Perez, 2002, p. 16). ${ }^{3}$ Durante a efervescência coletiva podemos observar como os víncul os sociais se constituem e verificar como os laços de parentesco, a vizinhança e a amizade ainda estruturam as relações sociais no cotidiano.

É preciso descrever as técnicas que envolvem a matança do porco, as práticas culinárias e a feitura do doce, mostrar como o evento festivo revela uma organização social e laços de solidariedade fortes, antes de tentar perceber a lógica que envolve a elaboração do chouriço: em uma cultura na qual há uma série de cuidados no que diz respeito ao corpo eà ingestão de alimentos, é estranho que elementos tão díspares - o sangue e o doce - possam ser misturados. 0 sangue, elemento natural por excelência, de perigoso torna-se comestível, com poucas restri-

3. Perez (2002, p.18) utiliza as noções de forma de sociação de George Simmel (1993). Segundo Perez, para esse autor "as formas funcionam como tipos-ideais, obtidos pela exageração de certas características dos dados reais", enquanto a sociação é o "processo permanente do vir-a-ser da vida social". A compreensão de que a vida social é um projeto de um vir-a-ser é comungada por muitos autores, entre estes Cornelius Castoriadis (1982; 2004). 
ções. A resolução do enigma encontra-se no lugar reservado ao doce de sangue no sistema alimentar e na organização da sociedade sertaneja.

\section{Etnografia do chouriço}

Práticas recorrentes nas sociedades camponesas européias, a criação e a matança do porco e, subseqüentemente, a preparação dos derivados da carne e do sangue foram levadas para a A mérica L atina. $E m$ diversas regiões do B rasil, o sangue é associado ao sal, à gordura e a outros temperos apimentados para a preparação de lingüiças de sangue, morcelas ou chouriços.

No sertão nordestino, encontramos uma variante: 0 sangue serve para a elaboração de um doce - o chouriço. Para nossa descrição, tomaremos alguns exemplos de festas de matança de porco realizadas na região do Seridó, no Rio Grande do Norte. ${ }^{4}$ Realizada durante um dia inteiro, a festa da matança de porco é um momento único durante o qual trabal ha-se e diverte-se muito. A festa é organizada para comemorar aniversários, casamentos, batizados, boa col heita, o Natal, a passagem de ano e outras ocasiões especiais. Embora nem todas as vezes que um criador de porco vende ou mata seu animal esteja obrigado a fazer o chouriço, é muito freqüente a real ização dessa festa. A festa é um acontecimento aglutinador e de efervescência social; revela laços de solidariedade que existem em uma sociedade agropecuarista ainda presente não hegemonicamente. A pesar das mudanças ocorridas nessas últimas décadas com o êxodo rural, quando muitas famílias que residiam no campo foram impulsionadas a migrar para os centros urbanos, causando muitos problemas, em especial a dispersão familiar, ainda se continua a criar porco e a fazer chouriço no Seridó. O bserva-se que essa tradição de família tem sido mantida

4. Os dados foram sistematizados após a realização de festas realizadas nos Sítios Carnaúba de Baixo (município de Carnaúba dos Dantas) e Olinda (município de São J osé do Seridó), nas cidades de A cari, Jardim do Seridó e Carnaúba dos Dantas. Essas observações foram realizadas para a elaboração da tese de doutorado de M aria Isabel Dantas, a ser defendida no Programa de Pós-Graduação em Ciências Sociais - UFRN. e/ou inventada por diversos grupos de parentes em alguns municípios do sertão seridoense, 0 que nos faz pensar ser este um pretexto para a preservação da memória do grupo e de uma tradição al imentar, assim como de criação, fortalecimento ou rompimento de vínculos sociais.

No processo de criação de porco, percebemos um verdadeiro sistema de reciprocidade em ação em que vínculos sociais são estabel ecidos entre os criadores e as pessoas juntadoras do comer do porco ou lavagem, como muitos assim se referem, durante o processo de engorda do animal. É uma prática recorrente em quase toda a região que, ao que nos parece, corresponde à organização da sociedade em torno da família ampliada.

\section{Vida e morte do porco}

Os colonizadores portugueses que vieram para o B rasil traziam com eles, também, seus animais domesticados que compunham uma família ampliada, composta da própria família e dos animais domésticos; entre eles, destacavam-se gado, porcos, caval os, galinhas, ovelhas e bodes. 0 sentido da família ampliada provinha em grande parte das condições materiais de subsistência para todo o grupo. Os animais que faziam parte desse modelo de família conviviam com os humanos, compartilhavam da mesma água, do mesmo ar, do mesmo ambiente e, às vezes, apresentavam muitas doenças, assinala Crosby (1993). Certamente, esse processo não foi tão diferente no N ordeste brasileiro.

No princípio da colonização, era dos animais que provinham os principais produtos da alimentação do seridoense. 0 cardápio era basicamente composto de alimentos provindos de animais e dos cereais produzidos na própria região, além de frutas silvestres, da caça e da pesca. Outras necessidades eram supridas com a comercialização ou troca de alimentos e animais excedentes, ou não, como ovos, carne de gado, de ovinos, de caprinos e de porco, galinhas caipiras, cereais, dentre outros. Com os proventos oriundos da comercialização ou da troca de tais produtos, eram adquiridos alimentos não produzidos na região, como rapadura, açúcar, feijão-de-corda ou de arranca, sal, café e as 
especiarias. As carnes de caça, de aves silvestres e de peixes, bastante utilizadas na alimentação, tinham um al to consumo nas ocasiões de seca, pel os menos entre os séculos XVIII eXIX, assinala Medeiros Filho (1983). Hoje, com o processo de industrialização e comercialização, a população tem acesso à maioria dos bens alimentícios produzidos regional mente, nacionalmente e, até, internacionalmente. $M$ algrado a diversidade de alimentos ofertada pelo mercado global, muitas práticas do passado ainda resistem no seio da população. $A$ criação doméstica de animais é um bom exemplo dessa permanência.

A ssim como aconteceu na Europa e em outras partes do mundo, no B rasil o porco tem desempenhado um papel fundamental na economia agropecuarista de muitas comunidades rurais. Sua carne, seu sangue e suas vísceras têm inspirado a invenção de comidas das mais simples às mais exóticas, além de ser um animal que pode servir de elo entre os indivíduos e as comunidades. A o gerar renda, tem se constituído como pretexto na produção de vínculos sociais, isto porque ao seu redor, ou no seu processo de criação e comercialização, está implícita uma série de transações simbólicas, sociais e econômicas que engendra muitas relações no mundo social.

No Seridó, a atividade de criação doméstica de porco continua sendo desenvolvida tanto no campo como na cidade, sendo na maioria dos casos feita em chiqueiros. $\mathrm{Na}$ zona rural, os chiqueiros são construídos nos quintais ou terreiros das residências e, na zona urbana, em áreas da periferia destinadas pelo poder público para tal atividade ou em terrenos particulares. Esse animal passa por um processo de engorda que dura de oito a doze meses e somente é abatido quando está nas condições de agrado do marchante. ${ }^{5} \mathrm{~A}$ exigência atual é que o porco tenha mais carne e menos gordura, enquanto no passado, segundo al guns marchantes carnaubenses, a compra de um porco estava diretamente relacionada à espessura de seu toucinho.

5. Profissional especializado na compra, no abate e na venda de carne de gado, porcos, ovinos e caprinos no mercado local e da região.
Na maioria dos casos, a criação está sob a responsabilidade das mulheres ${ }^{6}$ e representa uma fonte de renda para muitas famílias, chegando a garantir a sobrevivência de muitos. Para $M$ aria de Fátima Silva Santos, 49 anos, criadora de porco há mais de trinta anos, criar um porco "ajuda muito, tira a gente do sufoco [...]. Serve demais a pessoa, para comprar uma roupa para um filho, calçados. Dá trabal ho, mas serve para tudo no mundo".

0 porco é criado à base de restos de comida, frutas e legumes estragados, fol has verdes e, em alguns casos, de ração. Sua engorda é geralmente viabilizada por meio de juntas de restos de comida das casas dos parentes, amigos, vizinhos; de cozinhas de bares, restaurantes, pousadas, hotéis e de produtos estragados dos mercados, mercadinhos efeiras livres. A grande maioria dos criadores não dispõe de lavagem ou de comer de porco o suficiente para engordar o seu animal. E o interessante é que apesar do comer ser doado voluntariamente, o criador fica obrigado a retribuir a oferta. Paradoxalmente, a retribuição é voluntária e obrigatória; não fazêla pode ser motivo de desagrado e até de intriga por parte dos juntadores, conforme relata um criador de porco de J ardim do Seridó. Na transação há uma lógica econômica e uma força simbólica que obrigam o criador a retribuir a dádiva recebida na hora do abate do animal e/ ou na feitura do chouriço. ${ }^{7}$

No caso da zona rural, as condições de engorda do animal estão submetidas, quase sempre, às atividades agrícolas, pois são um bom inverno e uma boa safra de cereais e frutas que garantem que o criador vai ter animal todos os anos para abater; a isso, também, somando-se a junta de comer de porco entre os vizinhos dos sítios e da cidade. ${ }^{8}$ Poucas famílias podem

6. Embora a criação de porco fique a cargo da mulher, não é ela quem comercializa os animais no momento de sua venda. $A$ atividade é realizada pelos homens, excetuando-se algumas particularidades, em que a mulher é quem vende os animais.

7. Observa Mauss (2003), em sua teoria da reciprocidade, que o efeito da retribuição pode acontecer quando há na coisa dada uma força que obriga o donatário a retribuir.

8. Encontramos muitos criadores de porco transportando lavagem dos centros urbanos para os sítios em todos os municípios pesquisados. 
engordar um porco sem a colaboração de outras pessoas. Isso prova que a criatória de porco só tem sentido de ser e de existir pela coletividade, em uma ação compartil hada. A lém disso, é preciso ter uma mão boa para engordar o porco, segundo nos disse dona Raquel da Silva, 75 anos, ex-criadora de porco. $N$ as palavras dela: "Eu tenho uma mão boa para criar porco, para cuidar de porco. M inha mão não é de arruinar muito as coisas, não".

A lém dos cuidados com a higiene e com a saúde dos porcos, é a lavagem que garante a engorda do animal e, conseqüentemente, gera lucro e festa para o criador. Ela é um bem economicamente útil, mesmo sendo aquilo que não será mais utilizado pelos humanos. U ma expressão disso é o cuidado que tem o criador de porco, no momento do abate, em oferecer um torrado ${ }^{9}$ de carne ou uma prova do chouriço a quem juntou o comer e, na expectativa dos juntadores, de receberem algo pelo favor prestado. Entretanto, parece não ser apenas 0 aspecto econômico o mais importante nessa atividade. Criar um porco é uma grande oportunidade para o fortal ecimento de laços de parentesco e de amizade. 0 momento do abate do porco constitui um motivo de convívio social, de reunião da família e de amigos e, por que não

9. As carnes, frangos e peixes que acompanham a refeição principal são chamadas de "mistura". A carne verde é a carne crua, fresca e insossa que não passou por nenhum processo de transformação, em oposição às outras que são salgadas: a carne-de-sol ou carne-seca (sem osso), que é feita com a "carne de gado"; outros tipos de carne são salgados e consumidos no Seridó como, para a carne de boi, a carne de charque, as costelas, o pescoço, os miúdos e, para a carne de porco, as tripas e outras partes do porco (costela, toucinho, orelha, mocotó, cabeça etc.), a carne de bode seca, a carne de burro mulo ou jabá. A carne verde é mais utilizada durante as festas e nos finais de semana, enquanto a carne-seca ou as carnes salgadas fazem parte do cardápio do dia-a-dia, algumas são usadas para temperar o feijão. 0 termo torrado é utilizado para designar uma porção de carne verde em quantidade suficiente para uma pequena refeição, como também para se referir a um tipo de cozimento feito com a carne verde; neste caso diz-se carne torrada. É recorrente a doação de um "torrado" às pessoas que ajudaram a engordar o porco e que não podem participar ou não foram convidadas para a festa da matança de porco. No caso dos criadores que não realizam a festa da matança a prática mais comum é a divisão do arrasto entre os juntadores de comer de porco. 0 arrasto é composto do espinhaço, do fígado, do coração, dos bofes e dos rins do porco. Conforme veremos adiante, é o arrasto que é partilhado com os familiares, vizinhos e amigos e com os juntadores de comer de porco no dia do abate. dizer, de festar. ${ }^{10}$ Ora, a festa constitui-se como o paradigma da partilha de alimentos e de colaboração entre os seres humanos. É nela que presenciamos a transmutação de sangue em doce, de sangue em sabor e prazer.

\section{Os preparativos para a festa da matança de porco}

No Sítio Carnaúba de B aixo, nas proximidades da cidade de Carnaúba dos Dantas, no interior do R io G rande do N orte, dona A ngelita $M$ aria D antas, viúva, 69 anos, mãe de doze filhos nascidos e criados no sertão, reúne, pel o menos uma vez por ano, seus parentes e amigos para fazerem uma matança de porco. A ssim também faz dona Daluz Dantas, casada, 60 anos, dez filhos, criadora de porco, agricultora aposentada e morada desse mesmo sítio. Dona M aria L uíza de A zevedo, nove filhos, 83 anos, residente na cidade de J ardim do Seridó, também real iza festa muito semel hante à de dona $\mathrm{D}$ aluz eà de dona A ngelita. No caso desta, a festa, geralmente, ocorre nas comemorações do final do ano, momento em que toda a família se reúne. Há poucas pretextos para reunir a família inteira, pois, cada vez mais, os parentes moram em lugares distantes.

Entre outras ocasiões para matar o porco e fazer um chouriço, encontramos os aniversários, outras reuniões familiares e festas celebradas nos municípios (D antas, 2002). M as a incidência maior tem sido na segunda metade do ano, período da colheita do milho, do feijão, da batata e de outros produtos agrícol as que são imprescindíveis, juntamente com os restos de comida caseira, para a engorda do porco. Segundo dona Angelita, a prática de fazer chouriço foi herdada de seus antepassados e aperfeiçoada na convivência com uma mestra de chouriço famosa da localidade. ${ }^{11}$ Dona M aria Luíza

10. Nem todas as pessoas que criam porcos fazem chouriço, assim como há outras que produzem o doce sem a festa. Nesse caso, o sangue é aparado pelo marchante no matadouro oficial ou clandestino e doado à mestra ou à dona do chouriço.

11. Não dispomos de dados estatísticos suficientes para afirmar o número de mulheres e homens que fazem o chouriço na região do Seridó. 0 que podemos afirmar é que a grande maioria das (os) mestras (es) do chouriço reside ou já residiu na zona rural. Hoje, são poucas as pessoas que criam porcos 
aprendeu também com uma mestra da fazenda onde residia e hoje, apesar da idade, ainda é solicitada para fazer o chouriço na casa de amigos e parentes. Dona Daluz convida uma mestra (sua parenta) para fazer o chouriço na sua casa.

A matança de porco, acompanhada da feitura do chouriço, é uma atividade festiva que precisa ser preparada com muita antecedência, mesmo quando ainda não se sabe em que dia ela vai acontecer. Isso porque depende de al guns fatores: do ponto de engorda do porco, da junta das castanhas e das condições econômicas da família para adquirir os outros ingredientes e os temperos necessários à fabricação do chouriço.

A castanha de caju é um dos principais ingredientes do doce. $\mathrm{Na}$ região do Seridó sua colheita se dá entre os meses de setembro e outubro. A pós serem apanhadas, as castanhas devem ser secadas antes de serem assadas, porque, no chouriço, elas não podem estar nem verdes, nem muito secas. Além do mais, é necessário a dona de casa pedir aos parentes e amigos para eles irem juntando latas vazias de leite, de doce e de margarina, para colocar 0 doce. No passado, o chouriço era colocado em panelas de barro ou de alumínio.

$\mathrm{N}$ a semana que antecede a matança de porco, a família precisa realizar as seguintes tarefas: comprar os ingredientes e temperos para o chouriço; assar, quebrar e tirar a pele das castanhas; tirar e descascar os cocos; moer e pilar os temperos e a farinha de mandioca; recolher as latas vazias; limpar a casa e os terreiros; juntar e rachar a lenha para cozinhar o chouriço; contratar o marchante; alugar 0 tacho, e convidar as pessoas para a festa. 0 convite é feito a parentes (pais, filhos, irmãos, cunhados, tios, afilhados), vizinhos, amigos e outras pessoas.

0 convite aos parentes é parte do comprometimento solidário que existe entre eles, tornando-se praticamente uma obrigação. Os

e que fazem a festa da matança com a produção do chouriço. A ntigamente esta era uma prática bastante recorrente na zona rural, segundo muitos seridoenses. A pesar de ter sido mais freqüente no passado, ainda é comum a dona da festa contratar uma mestra famosa para fazer o chouriço. Isso acontece quando ela não domina toda a técnica de fabricação do doce ou quando não dispõe de condições físicas suficientes para dar conta de tantas tarefas. vizinhos que doaram o comer de porco também são convidados, assim como outros com quem são mantidos laços de solidariedade ou uma relação de compadrio. A inda pode ser feita, nessa ocasião, a retribuição a al gum convite que a pessoa tenha recebido em uma matança de porco ou em outra atividade festiva. Em se tratando dos amigos mais próximos, podemos dizer que o convite tanto pode vir dos donos da casa, como também dos filhos, e pode estar relacionado a laços de amizade, como a favores já prestados. É notável o caráter de retribuição presente nesse tipo de relação, o que fica mais explícito quando se trata de outros convidados que não têm vínculos, nem de parentesco nem de amizade com os anfitriões. Eles são chamados à festa porque já prestaram algum tipo de favor à família ou porque ela os admira. Geralmente são tratados como convidados e não estão obrigados a participar nas tarefas.

0 marchante assume um lugar de destaque na matança do porco. Geralmente é al guém de confiança da família, por ser acostumado a matar esses e outros animais domésticos. É com ele que são realizadas as transações comerciais de compra e venda dos animais domésticos. Entre os presentes, está o mexedor do chouriço, que geralmente é um conhecido de confiança da mestra ou da dona da festa a quem é entregue, sem cuidado, o tacho de doce. Para ajudar o mexedor, são necessários outros homens dispostos - isso supõe que sejam homens que não bebam muito -, uma vez que o trabal ho de mexer o chouriço exige cuidado e atenção e pode durar até oito horas.

A matança do porco, a comercialização e a distribuição da carne

Na região do Seridó, o abate dos porcos ainda é feito de forma tradicional, seja ele realizado nos abatedores públicos ou nas próprias residências dos criadores. 0 abate, na maioria dos casos, não obedece a uma simples razão econômica, apesar de estar subordinado às normas econômicas vigentes na sociedade. Reveste-se de uma eficácia social e simbólica, em que estão implicadas trocas sociais, morte do animal, tabus e interdições alimentares. 0 ritual de morte ou abate do animal constitui um 
grande motivo de festa e obedece a algumas regras restritivas. É uma tarefa exclusivamente masculina e, na maioria dos casos, é feita por al guém que não é da família do criador - exceto quando existe um marchante na família - e quando 0 animal está no ponto de ser abatido. ${ }^{12}$ Normalmente as crianças do sexo masculino são incentivadas a participarem do ritual desde cedo.

Diferentemente do que acontece nas matanças tradicionais de porcos em algumas regiões de Portugal, em que as mulheres são interditadas de participarem do ritual, ${ }_{13}^{13}$ aqui elas podem ou não participar, dependendo muitas vezes de decisões coletivas ou individuais. No entanto, mesmo que as mulheres isentem-se do momento da insensibilização do porco, é necessária a presença de uma delas no momento da sangria. É geralmente a mestra ou a dona da casa (ou outra mulher) quem apara e esfria o sangue que vai ser usado na fabricação do chouriço. N esse contexto, é inadmissível a sangria de um animal antes de ele estar morto. Vialles (1987) observa prática semelhante em outras sociedades, em se tratando de rituais de abate tradicionais e industriais ou em cerimônias em que animais são sacrificados às divindades.

A matança do porco é, a nosso ver, um evento prenhe de contradições. Dar-Ihes festa não é o bastante, é preciso dividi-lo com os outros, em festa ou não. É assim que fazem todos os criadores de porco. ${ }^{14}$ Eles preferem vender 0 animal arrobado ${ }^{15}$ ao invés de vendêlo em pé ou inteiro como acham melhor os marchantes. ${ }^{16} \mathrm{~A}$ razão disso é o cumprimento do pacto que simbolicamente assumiram com as pessoas que lhes ofertam lavagem e que ajudaram a criar esse animal. Conversando com muitos criadores de porco, percebemos a preocupação que eles têm em partilhar um pouco do

12. Há uma norma na região do Seridó de que um porco somente está no ponto de ser abatido quando ele passa de seis meses de idade. No caso do animal macho, somente após três meses depois de ter sido castrado. Não há a prática de consumo de bacorinhos.

13. Para saber mais sobre a matança tradicional de porco em Portugal, ver Nogueira (2004).

14. A queles que ousam desafiar a prática da retribuição têm problemas em encontrar lavagem para criar seus porcos.

$\overline{15 .}$ Com essa forma de venda do porco, o marchante compra as bandas e o criador fica com 0 arrasto, as vísceras, a cabeça e os mocotós que restou do animal com os juntadores. N essa forma de comercialização do porco, o criador fica apenas com 0 arrasto, com a cabeça, com as vísceras e com os mocotós. Parece inacreditável que tão pouca carne possa gerar festa e ainda ser partilhada. É certamente a força do princípio da reciprocidade em ação e o milagre do arrasto que se multiplica. A partilha ou a doação de um torrado é significante, pois criadores e juntadores estarão em festa no dia da matança de porco. Essa prática é fruto do processo de sociabilidade que acontece desde tenra idade. A prende-se desde pequeno que 0 porco é o animal que vai dar festa e lucro à família. A s crianças não são socializadas para eternizarem 0 animal. Elas vão aprendendo que um dia ele vai ser morto. $N$ ão há muito constrangimento nisso.

Nesse sentido, a metáfora da família ampliada é importante para pensar a forte dependência dos homens em relação aos seus animais no contexto do cotidiano seridoense. 0 porco é visto como um membro da família. Durante um ano inteiro, ele convive de perto com os humanos, compartilhando o mesmo espaço, recebendo nome, carinho e alimentação por parte de crianças e de mul heres; sobretudo a dona da casa. No dia da matança é preciso desumanizá-lo, tratando-o como um animal qualquer, entregando-o a um desconhecido para que se torne um objeto de consumo. No relato do agricultor, criador de porco e marchante José Ernano Dantas, 56 anos, essa idéia está bem clara, quando ele afirma por que não costuma abater os animais que cria. "Eu acho melhor vender aos outros porque fui eu quem criei. É mel hor matar dos outros do que matar o meu, porque um marchante nunca quer matar 0 que é seu, você sabe [...]. Eu não gosto disso, não."

Há um paradoxo na hora do abate desse animal queé criado com muito carinho: ao invés

\footnotetext{
16. Segundo alguns criadores do Seridó, os marchantes preferem a compra do porco em pé, porque adquirem-no mais barato e assim conseguem obter mais lucro com a venda de toda a carne. Malgrado esse tipo de pressão por parte dos marchantes, há uma forte resistência dos criadores em manter a prática da venda do porco arrobado. A nosso ver, esse tipo de transação é imprescindível para a criação e a manutenção de relações sociais entre os criadores e juntadores de comer de porco.
} 
de não consumi-lo como imaginaríamos, ele vai ser comido, incorporado, interiorizado, como símbolo do pacto que há entre ambos - mulher/ criadora ou homem/criador e porco, ou seja, é o fortal ecimento (concretização) dos laços de familiaridade que se reafirmam. É por isso que muitas criadoras de porco, mesmo não participando da morte do animal, não se sentem constrangidas em consumir um animal que lhes é familiar. No seu imaginário, elas sabem que um dia o animal que criam será abatido para Ihes propiciar lucro, alegria, festa, prazer, sabor, abundância, bonança e vida.

M esmo sendo 0 ato principal do abate um momento difícil de ser encarado, principal mente pelas mulheres, é o sangue que perturba os humanos, uma vez que ele remete à imagem da vida humana, o que contribui para a criação de tantas interdições e aversões ao sangue animal . Por mais paradoxal que nos pareça, 0 animal que foi criado com tanto carinho um dia morrerá para fazer surgir a vida. É no momento da sangria do animal que acontece a separação do sangue da carne, ou seja, do corpo e do sangue. 0 abate anuncia a passagem da vida para a morte (o abate), senão dizer, para a desanimalização da carne. É preciso ter a certeza de que na carne não há mais vestígios de vida, simbolizada no sangue. A liás, o cuidado com o sangue tem sido uma constantena maioria das culturas e inspirado a criação de muitos tabus e interdições.

\section{Os cuidados com o alimento da vida - o sangue}

A separação do sangue da carne parece ser uma exigência em muitas sociedades. $\mathrm{Na}$ maioria del as, 0 abate dos animais comestíveis, seja de forma tradicional ou industrial, ainda é realizado obedecendo ao processo de insensibilização do animal, antes da sangria, conforme as prescrições mosaicas. ${ }^{17} 0$ método tradicional

17. Na região do Seridó, o abate ainda é feito de forma tradicional, seja realizado nos abatedores públicos ou nas próprias residências dos criadores. Normalmente as crianças do sexo masculino são incentivadas a participar desde cedo do ritual. É inadmissível a sangria de um animal antes de ele estar morto. Vialles (1987) observa prática semeIhante em outras sociedades, em se tratando de rituais de abate tradicionais e industriais, como de cerimônias em que animais são sacrificados às divindades. de insensibilização pode ser real izado por meio de um golpe ou um tiro na fronte craniana, deixando 0 animal sem sentido. ${ }^{18}$ Somente após esse procedimento dá-se a sangria. Com ela, 0 marchante (ou o sacrificante, no caso dos rituais religiosos) tem a certeza de que 0 animal foi realmente abatido. Há uma lógica que pode explicar o modelo de abate tradicional. É inconcebível o consumo da carne de alguns animais, como porcos, bois, carneiros, ovel has, bodes e cabras, sem a insensibilização antes da sangria. Sangrar um animal vivo é um ato de grande cruel dade, marca de assassinato, prática que não deve ser exercida por um ser humano. ${ }^{19}$ Comer a carne com o sangue é o mesmo que comer a própria vida do animal e isso os seridoenses não suportam. Isso ajuda a explicar a rejeição ao consumo de carnes de animais encontrados mortos. Vialles (1987, p. 35-79), ao estudar o processo de desanimalização da carne em sociedades européias, mostra que, tanto nos abates tradicionais como nos industriais, é exercida a prática da insensi bilização dos animais antes da sangria. Quanto ao abate industrial, as explicações dadas pelos profissionais para a permanência dessa tradição são de que a manutenção do costume da sangria dá-se por motivos técnicos e higiênicos, isto porque ela proporciona qualidade e uma melhor conservação à carne. Tais observações não revelam a verdadeira realidade cultural que envolve a sangria, adverte Vialles. Para ela, a sangria é a certeza da morte do animal. Ela torna o animal um cadáver.

Será então que 0 homem do século $X X I$ ainda não consegue encarar 0 sangue em sua mesa ou realmente estamos tratando de um problema de higiene? A creditamos que esse enigma não se explica apenas por questões higiênicas. Ora, o trato com o sangue tem sido um problema em muitas culturas. Conforme Vialles, "cozinhar o sangueéuma coisa, consumir uma carne impregnada de seu sangue é uma

18. 0 uso do choque elétrico foi usado durante certo tempo nos abates tradicionais no Seridó. Hoje a prática inexiste, porque ela deixa a carne com uma aparência desagradável ou com muito sangue, informa um marchante do município de Jardim do Seridó.

19. No Seridó, esse preceito não se aplica rigorosamente às miúcas (galinhas, galos, patos, perus e guinés). Esses animais também podem ser abatidos sem o processo da insensibilização e da sangria. 
outra; o bife sangrento não é sanguinolento" $(1987$, p. 80 - 85). 0 fato de o sangue animal ser familiar ao homem não é suficiente para torná-lo insensível ao sangue humano. A o contrário, todos os seres humanos afirmam uma particular sensi bilidade à vista do sangue humano. No contexto do Seridó, há uma grande sensibilidade não apenas diante do sangue humano, mas também animal. Poucos são as comidas feitas com 0 sangue animal. A panelada, a buchada, o picado ou sarapatel, a frissura e 0 chouriço (o doce) são as únicas comidas em que se concebe a presença desse alimento na região. Excetuando-se o chouriço, todas elas podem ou não receber 0 sangue. $A$ inserção desse al imento depende de valores alimentares coletivos e individuais. 0 chouriço é a única comida que é inadmissível sem o sangue. Há uma variação do chouriço, conhecida por espé$\mathrm{cie}^{20}{ }^{20}$ que não recebe 0 sangue em sua fabricação. No entanto, por não conter esse alimento, ela não tem mais o status do chouriço, sendo uma outra comida.

M as há mais: mesmo o sangue de alguns animais sendo permitido na mesa do seridoense, seu consumo só é concebível em seu estado sólido e após ele ser aferventado. 0 curioso é que há uma exceção no caso do sangue usado no chouriço, uma vez que ele é misturado aos outros ingredientes do doce em seu estado natural. E ssa naturali dade com que se apresenta o sangue no chouriço é sintomática da forte rejeição que tem essa comida fora do contexto seridoense. Vimos que o processo da sangria é uma exigência em muitas sociedades, mas nem por isso o consumo deliberado do alimento da vida é permitido em seu estado natural. Em al gumas delas, o sangue animal é desperdiçado; enquanto em outras ele é recolhido para usos al imentares, industriais, religiosos ou para outros fins (Vialles, 1987). No caso do sangue do porco, os usos mais freqüentes estão na alimentação e na indústria. $\mathrm{Na}$ maioria dos casos dos abates

\footnotetext{
20. Segundo a seridoense Rita Emília da Conceição Nascimento, mestra de chouriço e de espécie, criadora de porco e agricultora, o doce de espécie recebe praticamente todos os ingredientes do chouriço, com exceção do sangue e da banha de porco. Seu cozimento dura em média de uma a uma hora e meia, enquanto 0 chouriço chega a cozinhar até oito horas seguidas.
}

estudados pela autora, o sangue é desperdiçado nos esgotos, sendo transmutado e descolorado por meio da água. ${ }^{21}$

Festa: comer a carne e o sangue do porco

Na região do Seridó, todas as partes do porco são consumidas, inclusive seu sangue que é transformado em chouriço. A abundância da comida corresponde à generosidade do animal, cuja carne é consumida no mesmo dia ou redistribuída entre parentes e amigos que não poderão participar da festa. Enquanto 0 doce cozinha, os participantes fazem festa. Conversam, trocam idéias, bebem, comem, dançam e trabal ham; a produção do doce e das comidas demanda muitas tarefas, que são divididas entre os homens, as mulheres e as crianças. As mulheres assumem as tarefas domésticas e os homens, os afazeres mais voltados para 0 exterior da casas. Entretanto, a participação de todos é fundamental para a criação ou o fortalecimento do sistema de trocas e de prestações. No final do dia e da festa, é servida a sobremesa - o chouriço, símbolo da abundância.

A boa comida que falta na mesa cotidiana é ofertada ou prestada no dia da festa como forma de o dono da casa ganhar prestígio diante dos outros. 0 mais importante é ter comida em abundância para of ertar aos amigos e parentes, ser generoso, visto que isso suscita respeito e admi ração dos convidados. 0 contrário é motivo de desonra. A mesa farta é um subterfúgio para demonstrar generosidade e obter 0 reconhecimento tão caro aos anfitriões. Parafraseando Valeri (1989), podemos dizer que uma atitude dessa natureza demonstra como a dimensão nutricional dos alimentos pode estar subordinada à simbólica. Nesse dia, a carne e 0 chouriço ganham caráter ostentatório diante dos convidados porque, na condição de melhores al imentos da casa, serão oferecidos aos presentes. $\mathrm{Na}$ ocasião, as comidas funcionam como al imentosdádiva, porque têm al to poder de troca.

21. Diz a autora que a água é o antídoto do sangue, ela pode sempre diluir o sangue. Ela permite que sua condição de líquido da vida dilua-se nos esgotos. Coincidência ou não, os abatedores estão localizados sempre próximos aos cursos dos rios ou dos esgotos domésticos. 
A oferta ou a distribuição do chouriço funciona como uma contraprestação, quando a mestra é agraciada com el ogios à gostosura do doce e à sua generosidade. Seu prestígio cresce. Isso demonstra que o chouriço não é um simples doce, mas um alimento que pertence a um sistema complexo alimentar organizado e parece ser uma estratégia para amenizar o caráter pesado e perigoso da carne de porco, transformando-a, também, em um alimento social e sem tanto perigo.

0 chouriço, mesmo sendo partilhado entre algumas pessoas, funciona com dádiva, pois uma parte é distribuída aos que ajudaram a engordar o porco e a real izar a festa. Pela própria dificuldade de fabricação, à custa de um grande trabalho, o produto tem, portanto, um valor de troca. Todos querem trabalhar para poder ganhar uma lata do chouriço ou apenas o al moço e uma prova do doce. Ele pode então assumir a forma direta de instrumento de competição social, uma vez que é um bem. ${ }^{22}$

A carne e o chouriço, no dia da matança do porco, são os al imentos mais abundantes para os seridoenses que criam esse animal. ${ }^{23} 0$ status desses al imentos garante-Ihes que possam ser repartidos, trocados, rifados, vendidos e até retribuídos. Isso se torna possível porque a produção do chouriço é o momento culminante da comunhão entre os indivíduos de mesmo sangue. M esmo se a festa do chouriço aparece como um momento de culto às origens e um elemento de identidade cultural, a chouriçada é, acima de tudo, um momento de grande efervescência social, no qual a comunidade constrói ações práticas que garantem uma continuidade e permanência.

\section{Para fazer um bom chouriço... ${ }^{24}$ \\ 0 cozimento do chouriço é geralmente feito em fogo a lenha, controlado pelo mexedor. É,}

22. É importante registrar que uma grande parte do chouriço é comercializada na própria comunidade entre os conhecidos e/ou entregue em mercados locais e de outras cidades. No Seridó, não se compra chouriço de uma mestra desconhecida. A marca da confiança é fundamental nesse tipo de transação. A inda encontramos a comercialização do doce por meio da rifa, prática recorrente no passado.

23. No caso do Nordeste brasileiro, o chouriço, a carne assada ou torrada, o picado ou sarapatel, a banha e as lingüiças são as carnes consideradas mais ricas. talvez, por meio do poder simbólico do fogo culinário, que o sangue, alimento impuro, transforma-se em comida menos perigosa e mais aceitável. L évi-Strauss (1991) lembra que é o fogo que transforma o alimento natural em cultural, o cru no cozido. Contudo, essa força destruidora do fogo é também ambígua, porque, mesmo domesticado, ele conserva seu caráter perigoso, tanto destrói como renova. Isso acontece, segundo Catherine Perlis, "porque queimar é destruir, mas é, também, fertilizar; queimar é desfigurar, mas é também purificar" (1993, p. 279).

A preparação do doce requer tempo e sabedoria, uma vez que seu cozimento élento e gradual: chega a durar até oito horas. Trata-se de uma mistura equilibrada de sangue e banha de porco, garapa ou mel de rapadura, castanha de caju assada e moída, leite de coco, farinha de mandioca e al gumas especiarias como cravo, canela, gengibre, pimenta-do-reino eerva-doce.

0 sangue é inicial mente misturado ao leite de coco num tacho de cobre, a uma parte da garapa, à farinha de mandioca, à castanha e a uma parte das especiarias. A chouriceira mexe com a mão a mistura de cor avermelhada com cuidado para "desemboloá-la". Depois é que o resultado dessa mistura é levado ao fogo (trempe), onde será cozido e mexido gradativamente atéchegar no ponto. A partir do início da fervura, é contado o tempo de cozimento, que pode durar até seis horas. 0 chouriço vai ao fogo contendo uma grande quantidade de ingredientes, tais como: farinha de mandioca, leite de coco, castanha moída, sangue, banha e temperos. 0 restante dos ingredientes vai sendo colocado aos poucos, exceto uma parte das especiarias e das castanhas, que é acrescida quando o chouriço está quase no ponto. A tarefa de mexer o chouriço deve ser contínua. É árdua e é entregue a um mexedor e a al guns ajudantes responsáveis, dispostos e cuidadosos para não deixarem o doce pegar no fundo do tacho, nem emboloar. M esmo assim, a tarefa é dividida entre quase todos os homens que participam da festa. A mestra sempre recebe a ajuda de ami-

24. Ver, no A nexo 1, a receita do doce, cujas medidas equivalem a um chouriço de cinqüenta rapaduras, para um rendimento de cinqüenta latas de quinhentos gramas. 
gas que também têm experiência na feitura do doce.

No final da tarde, a dona da casa anuncia que o doce está no ponto, após as amigas experientes confirmarem. As atividades redobram. As crianças são afastadas do local para evitar acidentes, sobretudo queimaduras com o doce quente. Mesmo assim, querem participar da retirada do chouriço. Como o tacho é extremamente pesado, sendo muito complicado sua reti rada da trempe, as latas são enchidas com 0 doce ainda nela. 0 fogo nesse momento é retirado para evitar que 0 chouriço pegue no fundo do tacho. Isso torna a tarefa muito perigosa. A Igumas mulheres experientes e cuidadosas transportam as latas cheias em bandejas até uma mesa, enquanto outras vão limpando os excessos das bordas das latas e enfeitando-as com castanhas. As crianças maiores participam nesse momento.

É chegada a hora de raspar o tacho, momento esperado por todos. Todos os convidados querem provar o doce ainda quente. A s crianças e também os adultos, de colheres na mão, querem raspar o tacho. Este é um momento singular!

\section{Fim de festa}

No finalzinho da tarde e após ter provado 0 doce, os convidados vão embora. Ficam os familiares e alguns amigos para o jantar, momento em que o chouriço já está quase frio e pode ser mais bem saboreado. Todos os participantes levam uma prova do chouriço. No final, todos têm a certeza de que uma tradição foi reatualizada.

$\mathrm{Na}$ partilha, são agraciados todos os convidados, os parentes e amigos, além das latas que serão mandadas para aqueles que não compareceram à matança do porco. Entre estes estão os juntadores de comer de porco, de latas e outros pessoas que contribuíram de alguma forma para a realização do chouriço. Recebem também uma lata do doce alguém que 0 dono da casa deva algum favor. É uma excelente oportunidade para retribuir o serviço prestado! Os parentes que residem em outras cidades também recebem o doce. 0 chouriço restante que não é comercializado é consumido pela família durante, pelo menos, uma semana. A contece que, levada pela sua generosidade, muitas vezes a dona da festa não guarda nenhuma lata de doce para o seu consumo próprio. 0 porco, inicial mente animal familiar, é transformado em dádiva e serve de pretexto para a circulação de bens e a prestação de serviços. Alimento social por excelência, 0 chouriço contém também as marcas da cultura.

\section{L eituras do chouriço}

Os clássicos, como M. M auss (1950) ou C. Lévi-Strauss (1985), ajudam-nos a decifrar as práticas culinárias e de comensalidade. M omento de efervescência social, uma forma lúdica de sociação, a festa da partil ha do porco pode também ser lida como um grande Potlatch durante 0 qual os bens materiais e simbólicos são trocados. Nos momentos festivos, há condições ideais à preparação, à distribuição, à exposição pública, à troca e à obtenção de prestígio. No momento da troca, por exemplo, é estabelecida uma ligação, na qual o que é dado ganha o status de dádiva e precisa ser retribuído. Entretanto, muitas vezes 0 alimento - dádiva a ser distribuída - é revestido de tabus e de interdições, dificultando assim a sua circulação dentro desse grupo social. Quando isso acontece, são acionados estratégias e subterfúgios para fazer com que 0 alimento de poder perigoso ganhe mais aceitabilidade entre as pessoas. A festa da matança de porco consegue ser um acontecimento capaz de agregar pessoas, de mantê-las juntas, apesar de tratar-se de uma ocasião em que é servida a carne desse animal e o doce, alimentos interditados para determinadas categorias de pessoas. Em algumas sociedades, a alimentação assume caráter de dádiva, possibilitando dessa forma o próprio convívio social. M auss (1974), com seu estudo sobre o sistema de troca e de prestações totais nas sociedades antigas, observa que os homens são motivados a criarem sistemas complexos e codificados de trocas e de prestações, visto que nesses momentos podem trocar e/ou dividir os alimentos entre parentes, amigos e até inimigos.

É a ocasião, para os organizadores da chouriçada, de mostrar a força da família, reunindo seus membros mais afastados, e de 
atualizar o seu poder econômico esua influência local por meio dos gastos alimentares e dos gestos de generosidade. É preciso retribuir o esforço de cada um, distribuindo com generosidade as partes do animal e o doce. A excepcional fartura presente durante a festa que se prolonga com a distribuição do doce opõe-se à economia cotidiana dos recursos naturais - não se deve esquecer que estamos numa zona semiárida e que existem problemas crônicos de abastecimento de água.

$\mathrm{Na}$ ocasião da festa, constata-se uma reafirmação da ordem social fundada na ajuda mútua e da existência de uma sociabilidade na qual, apesar do clima de reunião, podem se ler fortes divisões, sobretudo entre homens e mulheres. $M$ arcado pela excepcionalidade, 0 dia do chouriço destoa dos outros. Efetivamente notamos a ausência da carne de porco nos cardápios cotidianos dos sertanejos. 0 perigo envolvendo a transformação do animal doméstico em al imento raramente consumido persiste após o cozimento, pois a carne e o doce continuam sendo pensados como carregados e são proibidos às mulheres grávidas, aos enfermos, aos operados e aos anciãos. A proibição alimentar marca a entrada do animal na cultura. ${ }^{25} \mathrm{No}$ momento da festa, muitas pessoas que estão interditadas de comer a carne de porco ousam transgredir as prescrições al imentares e chegam a provar da carne e do chouriço.

A ssim, podemos entender a chouriçada como um ato essencial mente cultural, em que a natureza (sangue) é superada e transformada em alimento (cultura) (Lévi-Strauss, 1975b). É importante notar que, geral mente, o manejo do sangue e da carne de porco requer cuidados especiais devido ao estatuto específico desse animal doméstico, apesar de ele não deixar de ter um estatuto ambíguo, pois sua carne é considerada como impura (L each, 1989, p. 83116; M illet, 1995; Fabre-Vassas, 1994). As marcas naturais - não-domesticadas - da feminilidade, como o sangue menstrual, entram em incompatibilidade com a cozinha em várias sociedades humanas; aqui encontramos uma

25. Quem não pode comer a carne do porco é servido com outras carnes descarregadas, como galinha caipira ou carne de criação. 0 termo criação é empregado para designar a carne de caprinos e de ovinos. atualização do sistema das proibições que dizem respeito aos animais (D ouglas, 1992). A família, elemento central na organização da sociedade sertaneja, reúne-se ocasionalmente em torno de uma atividade al tamente perigosa e sexual mente marcada: a transformação do sangue e da carne de porco em alimentos. A o sangue, acrescentam-se o açúcar e muitos temperos; preparação que será cozida com bastante cuidados em fogo brando durante horas, sob o olhar das mulheres que têm uma grande experiência culinária. A preparação, a degustação criteriosa do chouriço, acompanhada por comentários, pertence ao domínio feminino. A cozinha eo interior da casa tornam-se lugares reservados às atividades culinárias, tendo um caráter quase íntimo, onde devem reinar a ordem e a limpeza. A limento essencial mente feminino, o sangue/doce opõese, simbolicamente, à carne que deve ser ingerida rapidamente e na sua total idade, sobretudo pelos homens. Preferencialmente torrada ou assada no fogo alto, o saboreio da carne acompanha uma bebida quente e uma efervescência que se traduz em excesso e desordem: barulho, dança, comilança, bebedeira, fofoca etc. 0 chouriço não é simplesmente um doce, mas um grande acontecimento festivo, um momento propício ao saboreio de uma doce dádiva.

0 forte simbolismo que envolve o porco 0 animal, a carne e 0 sangue -, bem como os cuidados relativos à sua ingestão estão relacionados a fatores simbólicos, nutricionais e sociais. Fatores estes responsáveis pela transformação de al imentos proibidos em al imentos-dádiva que são capazes de gerar relações sociais e revelar uma cultura tradicional ainda performativa. As escolhas passam também pelo tratamento da carne: salgada, seca, fresca, verde, muciça, ${ }^{26}$ com osso, podre, estragada, crua, cozida, torrada, assada, dentre outras. As escolhas alimentares obedecem a lógicas culturais, nutricionais, emocionais, simbólicas, sociais, econômicas e religiosas. Porém, a carne de porco é freqüentemente proibida na região do Seridó: muitas vezes a carne não pode ser consumida por al gumas categorias de pessoas, como doentes, operados, crianças pequenas, velhos, mulheres paridas e menstruadas, dentre outras estados.

26. Carne sem osso e mole. 
A qualidade carregada ou descarregada atribuída a alguns alimentos designa comida proibida ou liberada, respectivamente. Essa idéia está associada tanto ao uso dos al imentos como a sua eficácia nutricional e simbólica. Um alimento é carregado quando ofende ou faz mal e descarregado quando não ofende ou não faz mal à saúde. Essas classificações estão ligadas à idéia de que determinados al imentos têm um efeito destruidor quando são ingeridos, principalmente quando o organismo está fraco ou aberto e não pode suportar tal efeito. Caso as proibições não sejam cumpridas, as pessoas podem sofrer malefícios físicos. Podemos apontar que tais denominações são semelhantes às qualidades de alimentos reimosos (com reima) e não-reimosos (sem reima) observadas por M aués (1980) e Peirano (1975), em comunidades de pescadores, respectivamente, nos povoados de I tapuá no Pará e I caraí no Ceará.

M esmo sendo por meio das técnicas de preparação do chouriço que o sangue se desnaturaliza e, misturado a ingredientes e especiarias, perde seu gosto natural de sangue - uma vez que o doce, mesmo tendo sabor forte, não apresenta vestígios nem gosto desse alimento -, é todo o simbolismo que envolve sua feitura e seu consumo que exerce função primordial e determinante no evento. Parece existir um valor estético diferenciado para o chouriço, que é doce e é mais aceito, em relação à carne, que é sal gada, porque esta, mesmo sendo temperada e cozida em alta temperatura, não perde seu estado de carne de alimento perigoso e carregado. No entanto, apesar de serem proibidos para al gumas categorias de atores, isso não os impede de ser alimentos social izáveis, partilháveis e festivos.

Como parte do sistema al imentar seridoense, a carne e o sangue de porco têm uma força simbólica capaz de produzir uma festa. 0 consumo de alimentos está ligado a espaços, tempos, práticas, situações e comportamentos coletivamente vividos e imaginados. A qui, podemos observar um sistema alimentar que informa sobre a organização social e as representações simbólicas da sociedade sertaneja: é a ocasião de trocas, distribuições e retribuições, quando se realiza o exercício da dádiva, apesar de esses alimentos serem revestidos de tabus e interdições. A festa propicia a criação, a manutenção e o rompimento de vínculos sociais entre os indivíduos, em que os atos de dar, receber e retribuir fazem parte de um ciclo, não podendo ser considerados isoladamente, como adverte Godbout (1999) a respeito da análise das regras da dádiva. Para ele, essas etapas são igualmente importantes no estabelecimento das relações sociais e não apenas o momento do receber, como isolou abstratamente $\mathrm{M}$ arcel M auss em sua análise da dádiva.

No sistema al imentar do seridoense, a carne do porco - apesar das interdições - está presente desde o período da colonização, juntamente com a carne de gado, de caprinos e de ovinos. Fazem parte também da al imentação peixes, cereais, frutas e alguns legumes. No entanto, a carne que também assume posição relevante nesse contexto é abundante apenas na mesa das famílias mais abastadas, aparecendo na do pobre sobretudo em ocasiões especiais (festas, doenças, partos). 0 consumo da carne, além de exercer um papel fundamental na nutrição da população, uma vez que ela é considerada um al imento forte e que dá sustância, constitui um privilégio, sendo sinônimo de bem-estar e até de poder. Observa Contreras (2002) que o consumo de carne em sociedades estratificadas e hierarquizadas funciona como uma elemento de diferenciação social.

Entretanto, devido ao processo de interrelação espacial e cultural e à urbanização, a dieta seridoense vem se modificando substancialmente, sofrendo interferências e, com isso, a carne vem sendo substituída por outros alimentos. Hoje, podemos encontrar uma grande diversidade de produtos, apesar da resistência aos padrões culturais dessa população, marcados por traços sociais esimbólicos oriundos de uma sociedade tradicional (M edeiros, 1997). N esse sistema al imentar, a carne e o doce não atendem apenas a necessidades fisiológicas; a alimentação cria um sistema de comunicação no qual está implicado um conjunto de símbolos que servem de critérios de pertencimento e identidade para esse grupo social, além de gerar 0 processo de reciprocidade e de intercâmbio interpessoal. A s práticas alimentares são fundamentais na construção, na manutenção e na reprodução das sociedades humanas, isto porque 
produzem relações sociais em que estão presentes tanto pactos como conflitos.

A ssim, o chouriço ocupa um lugar privilegiado nas práticas alimentares e festivas do sertão nordestino. Revela uma organização social em torno da família estendida e mostra caminhos para apreender a dinâmica da sociedade: a divisão sexual dos papéis sociais, a delimitação dos espaços de trabalho e de sociabilidade, a distribuição das tarefas domésticas por faixa etária, a hierarquia e a reafirmação da autoridade no interior do grupo, dentre outros aspectos. A ssim, ao realizar uma descrição da matança e da transformação do porco em alimentos altamente perecíveis e, ao mesmo tempo, val orizados cultural mente, comprovamos a atualidade do vel ho conceito maussiano de fato social total que nos ajuda na descoberta de uma lógica cultural que possibilite a transformação do sangue em al imento.

Se as técnicas culinárias e as festas são vias de conhecimento das sociedades humanas, elas aparecem, no final da análise, como marcas identitárias fixadas pela tradição. Longe de serem estáticas, modificam-se em virtude dos contextos socio-históricos e das necessidades de legitimação de uma cultura. A autenticidade é afirmada como sendo o traço principal de um patrimônio comum que vem, cada vez mais, transformando-se em valor de mercado. N esse sentido, o chouriço, alimento " $100 \%$ sertanejo", torna-se a marca registrada de um lugar e de uma história constantemente em processo de reinvenção.

\footnotetext{
A bstract: This paper is a presentation of ethnographic material on the Pig Slaughter Feast and on the production of a sweet made in the Serido region of the Rio Grande to Norte, Brazil: the chourico. This sweet is one of the defining components of the "Seridbense" identity and here we will analyze it as an imaterial heritage. Given that the consumption of food is associated with times, places, practices, events and manners collectively lived and imagined, by investigating this eating practice we have the opportunity to explore a food system that reveals the "Sertaneja" society's symbolic logic and organization. The Pig Slaughter Feast is an occasion for exchange, distribution and retribution. It is the time to practice reciprocity, even though a series of taboos and interdictions shroud the food. During the feast, we can abserve elements of the local symbolic systems (values,
}

beliefs, representations and taboos) and social aspects. The strong symbolism involved in the pork meat and blood, as well as in its ingestion, is related to symbolic, social and imaginary factors responsible for the transformation of this forbidden food into "gift-food." such "bift-food" generates social relationships and reveals a still performative traditional alture.

K ey-words: chouriço; food system; Seridó (R N)

\section{Referências}

ARNA IZ, M abel Gracia (Coord.). Somo lo que comemos: estudos de alimentación y cultura em España. B arcelona: Editorial A riel, S.A., 2002.

AUGUSTO, J osé. A região do Seridó. Natal: Edições Cactus, 1961.

CASCUDO, L uis da Câmara. Dicionário do folclore brasileiro. 2. ed. Rio de Janeiro: Instituto Nacional do Livro; M EC, 1962.

. História da alimentação no Brasil. 3. ed. Sã̃o Paulo: Editora Global, 2004.

CA STORIA DIS, Cornelius. A instituição imaginária da sociedade. Tradução de G uy Reynaud. Rio deJ aneiro: Paz eTerra, 1982.

Figuras do pensável: as encruzilhadas do labirinto. Tradução de Eliana A guiar. Rio deJ aneiro: Civilização Brasileira, 2004, v. VI.

CAVIGNAC, Julie. M émoires au quotidien. Histoire et récits du sertão du RN. (B résil). Nanterre: Université de Paris X , 1994.

CONTRERA S, J esus. Carne ansiada, carne estigmatizada: Ios aspectos culturales en el consumo de carne. In: GRA CIA , M abel (Coord.). Somos lo que comemos: estudios de alimentación y cultura en España. B arcelona: Editorial A riel, 2002.

CORTONESI, Alfio. Cultura de subsistência e mercado: a al imentação rural e urbana na baixa I dade M édia. In: FLA NDRIN, J ean-L ouis; M ONTA NA RI, M assimo. História da alimentação. Tradução de L uciano Vieira M achado e G uilherme J. F. São Paulo: Estação L iberdade, 1998.

CROSBY, Alfred W. Imperialismo ecológico: a expansão biológica da Europa, 900-1900. T radução J osé A ugusto Ribeiro e Carlos A fonso $M$ alferrari. São Paulo: Companhia das L etras, 1993.

DA NTA S, M aria I sabel. D o monte à rua: cenas da festa de N ossa Senhora das Vitórias. Natal, 2002. Dissertação (M estrado em Ciências Sociais) - UFRN. DOUGLAS, Mary. De la souillure: essai sur les notions de pollution et de tabou. Paris: La Découverte, 1992. 
DURK HEIM , Émile. As formas el ementares da vida religiosa: sistema totêmico na A ustrália. T radução deJ oaquim Pereira N eto. São Paulo: Paulinas, 1989.

Representações individuais e representações coletivas. Sociologia, pragmatismo e filosofia. Porto: Ed. Rés, s.d.

DUVIGNA UD, J ean. F estas e civilizações. Tradução de L. F. Raposo Fontenelle. Fortaleza: Edições Universidade Federal do Ceará; Rio de Janeiro: Tempo B rasileiro, 1983.

FA BRE-VASSA S, Claudine. La bête singulière. Les juifs, les chrétiens et le cochon. Paris: Gallimard, 1994.

FARIA, Juvenal Lamartine de. A limentação. In: Velhos costumes do Seridó. Natal: Fundação J osé A ugusto, p. 33-36.

FERREIRA, A urélio Buarque de Holanda. Novo Aurélio - século XXI. Rio deJ aneiro: Nova Fronteira, 2002.

FISBERG, M auro; WEHBA, Jamal; COZZOLINO, Silva M . Franciscato. U m, dois, feijão com arroz: a alimentação no Brasil de norte a sul. São Paulo: A theneu Editora, 2002.

FLA NDRIN, J ean-L ouis. A alimentação camponesa na economia de subsistência. In: FLA N D RIN, J eanLouis; M ONTANARI, Massimo. História da alimentação. Tradução de Luciano Vieira M achado, Guilherme J. F. São Paulo: Estação Liberdade, 1998. FREIRE, Gilberto. Casa grande \& senzala. São Paulo: Editora osé Olimpio, 1980.

GEERTZ, Clifford. A interpretação das culturas. Rio de J aneiro: LTC, 1989.

0 saber local: novos ensaios em antropoIogia interpretativa. Tradução de Vera M ello J oscelyne. 3. ed. Petrópolis, RJ : Vozes, 1997.

GODBOUT, Jacques T. 0 espírito da dádiva. Tradução de Patrice Charles F. X. Wuillaume. Rio de J aneiro: Ed. Fundação Getúlio Vargas, 1999.

GODELIER, M aurice. Antropologia: textos selecionados. São Paulo: Á tica, 1981.

LA M A RTINE, Oswaldo. Sertões do Seridó. B rasília: Centro Gráfico do Senado Federal, 1980.

LANNA, M arcos P. D. A dádiva divina: troca e patronagem no N ordeste brasileiro. Campinas, SP: Ed. Unicamp, 1995.

LEA CH, Edmund. A humanidade e a animalidade. In: A diversidade da Antropologia. Lisboa: Ed. 70, p. 83-116, 1989.

LÉVI-STRA USS, Claude. As formas elementares do parentesco. São Paulo, Edusp, 1975a.

Totemismo hoje. Tradução de Malcolm B. Corrie. Petrópolis: Vozes, 1975b.
. Antropologia estrutural I. Rio de Janeiro: Tempo B rasileiro, 1985. 1991. . 0 cru e o cozido. São Paulo: B rasiliense,

0 pensamento selvagem. Tradução de Tânia Pellegrini. São Paulo: Papirus, 1997.

M ACÊDO, M uirakytan Kennedy de. A penúltima versão do Seridó: espaço e história no regionalismo seridoense. Natal, 1998. Dissertação (M estrado em Ciências Sociais) - Universidade Federal do Rio Grande do N orte.

M ACIEL, M aria Eunice. Churrasco à gaúcha. Porto A legre: Horizontes A ntropológicos. A no 2, n. 4, p. 34-48, jan./jan., 1996.

MACIEL, M aria Eunice; MENA SCHE, Renata. Alimentação e cultura: identidade e cidadania. Você tem fome de quê? Disponível em: http://adital.org.br/ asp2/notícia-asp? A cesso em: 4 jan. 2004.

MARY, Douglas. Pureza e perigo. São Paulo: Perspectiva, 1976.

M A RV IN, Harris. Vacas, porcos, guerras e bruxas. Rio deJ aneiro: Civilização B rasileira, 1978.

M AUÉS; M aria Angélica; MAUÉS, Raymundo Heraldo. $O$ folclore da alimentação: tabus al imentares da A mazônia. B elém: UFPA, 1980.

M A USS, M arcel. Essai sur le don. Forme et raison de l'échange dans les sociétés archaïques. In: Sociologie et anthropologie. Paris: Puf, 1950. p. 142279.

- Antropologia e sociologia. Tradução de Paulo N eves. São Paulo: Cosac \& N aify, 2003.

MEDEIROS FILHO, Olavo de. Da alimentação: In: Velhos inventores do Seridó. B rasília: Centro Gráfico do Senado F ederal, 1983.

M EDEIROS, M aria das Dores (Org.). Seridó antigo: história e cotidiano. 2. ed. Natal: EDU FRN, 1997.

M ILLET, J acqueline. M anger du chien? C' est bon pour les sauvages! , L'H omme, 136, 1995. p. 75-94.

M ONTANA RI, M assimo. Estruturas de produção e sistemas alimentares. In: FLA N DRIN, Jean-L ouis; M ONTA NARI, M assimo. H istória da alimentação. Tradução de L uciano Vieira M achado, GuilhermeJ . F. São Paulo: Estação Liberdade, 1998.

M ORAIS, Célia Márcia Medeiros de. Fazer um chouriço é um rebuliç̧o!!! N atal, 2002a. [M imeo.]

. Chouriço brasileiro, conforme Câmara Cascudo. Natal, 2002b. [M imeo.]

NOGUEIRA, Sandra. A criação tradicional de porcos em Portugal: análise antropológica de regras sociais, tabus e comportamentos. Disponível em: httpw ww. antropologia.com.br/art/colab/a8snogueira.pdf. A cesso em: 4 jan. 2004. 
PASSOS, M auro (Org.). F esta na vida: significado e imagens. Petrópolis, RJ: Editora Vozes, 2002.

PEIRANO, Mariza Gomes e Sousa. A favor da etnografia. Rio deJ aneiro: Relume-D umaré, 1995.

. Proibições alimentares numa comunidade de pescadores. Brasília, 1975. Dissertação (M estrado) - UnB.

PEREZ, Léa F reitas. A ntropologia das efervescências. In: PASSOS, M auro (Org.). A festa na vida: significados e imagens. Petrópolis, RJ : Vozes, 2002.

PERLIS, Catharine. Fogo. In: Enciclopédia Einaudi, Homus-Domesticacao. Cultura material - Casa da M oeda, 1989, v. 16.

POULAIN, Jean-Pierre. Sociologias da alimentação. Tradução de R ossana P. da C. Proença, Carmen S. Rial e Jaimir Conte. Florianópolis: Editora da URSC, 2004.

SANTOS, M ilton. A natureza do espaço: técnica e tempo - razão e emoção. São Paulo: Hucitec, 1996.
SA U M ADE, Fréderick. Chasseur, torero, boucher: le triangle sémantique du sang animal. L'Homme, 136, 1995. p. 113-122.

SAVA RIN , B rillat. A fisiologia do gosto. Tradução de Paulo N eves. São Paulo: Companhia das L etras, 1995.

SIM M EL, George. Sociabilidade: um exemplo de sociologia pura ou formal. In: MORAIS FILHO, Evaristo (Org.). Coletânea. São Paulo: Á tica, 1993. VALÉRI, Reneé. Alimentação. In: Enciclopédia E inaudi, H omo-D omesticação. Cultura material. Lisboa: Imprensa nacional - Casa da M oeda, 1989, v. 16.

VELHO, Otávio Guilherme C. A. Introdução. In: Hábitos alimentares em camadas de baixa renda. Relatório do Grupo de Pesquisa do M useu N acional. Rio de J aneiro: M useu Nacional, 1977.

VIA L LES, N oélie. Le sang et la chair: les abattoirs des pays de I'A dour. Paris: Ed. De la M aison des Sciences del'H omme, 1987.

\begin{tabular}{|c|c|c|}
\hline \multicolumn{3}{|c|}{ Anexo 01} \\
\hline INGREDIENTES & MEDIDAS & UTENSÍLIOS \\
\hline \multicolumn{2}{|l|}{ Porco } & \multirow{3}{*}{$\begin{array}{l}\text { Para es quentar a água (pelar o porco) e } \\
\text { cozinhar o doce } \\
1 \text { trempe (tripé de pedras) } \\
1 \text { tacho de ferro fundido de } 70 \text { a } 100 \text { litros }\end{array}$} \\
\hline Sangue de porco & $\begin{array}{l}2 \text { litros ou o sangue de um } \\
\text { porco de } 100 \text { quilo }\end{array}$ & \\
\hline Banha de porco derretida/líquida & 1 litro e meio & \\
\hline \multicolumn{2}{|l|}{ Especiarias } & \multirow{2}{*}{$\begin{array}{l}\text { Para matar, sangrar e esquartejar o porco } \\
\text { Machado grande e faca }\end{array}$} \\
\hline Cravo & 400 gramas & \\
\hline Canela & 400 gramas & \multirow{8}{*}{$\begin{array}{l}\text { Para cozinhar o chouriço } \\
\text { Para temperos: } \\
1 \text { moinho manual } \\
1 \text { pilão de mão grande de madeira } \\
\text { Para preparar os ingredientes: } \\
\text { Bacias de alumínio (flandre) ou plástico } \\
\text { Peneiras de ferro } \\
1 \text { pote de barro ou um balde grande para } \\
\text { derreter as rapaduras }\end{array}$} \\
\hline Gengibre & 250 gramas & \\
\hline Erva-doce & 400 gramas & \\
\hline Pimenta-do-reino (opcional) & 150 gramas & \\
\hline \multicolumn{2}{|l|}{ Ingredientes } & \\
\hline Rapadura (garapa ou mel) & 50 rapaduras de 500 gramas & \\
\hline Castanha de caju assada e moída & 3 quilos & \\
\hline Leite de coco & 5 litros $(12 \operatorname{cocos})$ & \\
\hline Farinha de mandioca fina e peneirada & 50 xícaras de chá (6 quilos) & \multirow{4}{*}{$\begin{array}{l}\text { Para colocar o chouriço de pois de pronto } \\
\text { Panelas de barro } \\
\text { Latas de leite em pó vazias } \\
\text { Depósitos de plástico ou de alumínio }\end{array}$} \\
\hline $\begin{array}{l}\text { Castanhas para enfeitar as latas com } \\
\text { chouriço }\end{array}$ & 500 gramas & \\
\hline \multicolumn{2}{|l|}{ Lenha } & \\
\hline $\begin{array}{l}\text { Lenha seca de jurema preta e / ou } \\
\text { catingueira }\end{array}$ & $1 / 2$ metro & \\
\hline
\end{tabular}

